\title{
Mapping and Size Estimation of Key Populations on HIV Surveillance in Nepal
}

\author{
Poudel $\mathrm{T}^{1^{*}}$, Gupta $\mathrm{S}^{2}$, Bhattarai Rajan ${ }^{3}$, Rawal BB ${ }^{4}$ \\ ${ }^{1}$ Professor, ${ }^{2}$ Assistant Professor, \\ Department of General Practice and Emergency Medicine, \\ Gandaki Medical College and Teaching Hospital, Pokhara, Nepal \\ ${ }^{3}$ Deputy Chief of Party, Save the Children International, Nepal, ${ }^{4}$ NCASC, Nepal
}

\begin{abstract}
Introduction: The HIV epidemic in Nepal is mainly concentrated among key populations, including people who inject drugs, gay men and other men who have sex with men, transgender people, female sex workers, and male labor migrants and their spouses. In countries with this type of concentrated HIV epidemic, the size of the key population estimation is important to address the national epidemic.
\end{abstract}

Objectives: The study has been designed to estimate the district and national level size of key populations at risk of HIV infection and providing a foundation for policy and programing and to guide the national response to address HIV epidemic.

Methods: This is a prospective mapping exercise study done in 44 districts of Nepal. Semi-structured interview were carried out among key populations members as well as non-key population key informants who were familiar with the local situation in and around the high prevalence areas. The study was conducted from August until November 2016. The collected data has been complied on Census and Survey Processing

Keywords

Female sex workers, Gay men, HIV,

Male labor migrants, Transgender,

Corresponding Author

*Dr. Tarun Paudel, MBBS, MDGP

Professor

Department of General Practice \&

Emergency Medicine

Gandaki Medical College \& Teaching

Hospital, Pokhara, Nepal

Email:drtarunpaudel@gmail.com
System and analyzed using Statistical Package for the Social Science software package 16 version.

Results: The national estimates of key populations were FSW around 54,207, MSM/MSW/TG around 112,150 of which men having sex with men were 67,292. The PWID individuals range around 34,487.

Conclusion: To fast track the response to achieve global 90-90-90 targets for the continuum of prevention to care, the country is updating its understanding of key population sizes and risk behaviors in different geographical area.

\section{INTRODUCTION}

The HIV epidemic remains concentrated among people who inject drugs (PWID), gay men and other men who have sex with men (MSM), transgender people (TG), female sex workers (FSW), clients of sex workers, such as male labor migrants (MLM) who travel to high HIV prevalence areas of India, and the sexual partners of all these groups. In countries with this type of concentrated HIV epidemic, the size of the key population is critical information to help guide the national response, and provide a foundation for the development of policies and programs ${ }^{1}$.

Countries with concentrated HIV epidemics conduct studies to estimate the number of key population members with specific risk behaviors such as buying and selling sex, having unprotected sex with multiple partners and clients, and sharing needles and injecting equipment. There are several methods for estimating sizes of key populations including census, nomination enumeration through mapping, and survey-based methods, including multiplier, capture-recapture and network scale-up ${ }^{2,3}$. 
This is the first study done throughout the country among key populations. The main objective of our study on the Mapping and Population Size Estimates (PSE) exercise was to produce district and national level size estimates of key populations (FSW, MSM, TG, MSW and PWID) at the risk of HIV infection. To help better understanding of key population sizes and risk behaviors in different geographical area of Nepal and providing a foundation for policy and programming and to guide the national response to achieve the Global 90-90-90 targets for the continuum of prevention to care for our key populations.

\section{METHODS}

Our study uses the mapping exercise and size estimation methods to obtain direct estimates of key populations. The mapping field work study was done in multiple stages: Premapping, level 1- mapping, level 2- mapping and district level validation of the data obtained. The study was carried out in 44 districts which were categorized into six epidemic zones (Eastern Hills, Far-West Hills, Highway, Kathmandu Valley, Remaining Hills, and West and Mid-West Hills. The districts were selected on the basis of behavior surveillance survey showing epidemiologically increased numbers of key populations residing within these districts. Each district was chosen as the unit of the present study (Fig 1).

With the help of key populations networks and local community mobilizes within each districts list hotspot areas where indentified. For Data collection in the field, nine field research teams were mobilized. Each team was composed of a quality controller, a supervisor, four to six field researchers, and one local motivator from each key population group. At the hotspot level, one researcher and one key population member were mobilized to conduct in-interviews after taking verbal consent from the participants. The study was carried out from 23 August 2016 till 28 November 2016.

The database was designed using Census and Survey Processing System (CSPro) with built-in checks for data entry errors and enabling of skip patterns as designed in the data collection forms. The study was approved by IRB of Nepal Health Research Council meeting of 2016. The method of extrapolation was used to calculate the proportion of adult males (in case of MSM and PWID) and the proportion of adult females (in case of FSWs) in the mapped district, and then multiplied that proportion by the number of adult males and adult females (respectively for MSM, PWIDs and FSW) in the unmapped districts.

\section{RESULTS}

The distribution of 44 mapped districts included in our study is in shown in Table 1 . The maximum number of key populations: FSW, MSM/TG/MSW and PWID and their hotspots were highest in Kathmandu valley. Our study showed the top four districts with sex solicitation spots numbers were Kathmandu valley-613, followed by Rupendehi-145, Dhanusha-110 and Sunsari-101. The lowest number of FSW spots among mapped districts was found in Syangja-4 (Fig.2, Fig.3 and Fig.4). The national estimates of FSW are 54,207 which represent $0.58 \%$ of the adult female population (Table 2). The national estimates MSM/MSW/TG around 112,150 which is $1.34 \%$ of total adult male population (Table 3 ). The PWID individuals range around 34,487 which is $0.19 \%$ of the adult population (Table 4).

Fig 1: Mapping Districts of Nepal

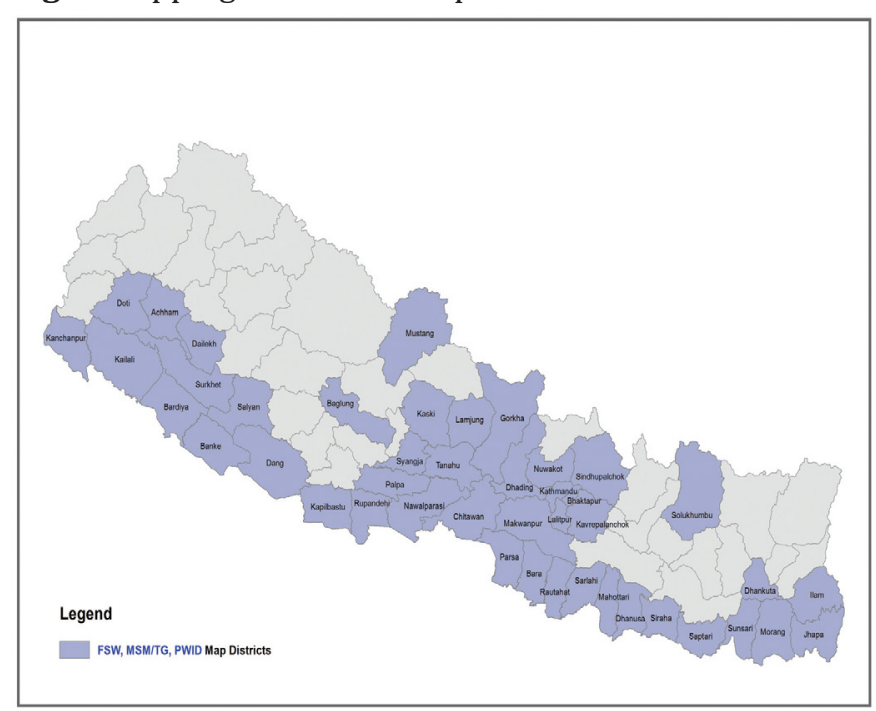

Table 1: Number of mapped, unmapped and extrapolated districts for FSWs, MSM/MSW/TG, and PWIDS

\begin{tabular}{|c|c|c|c|c|c|c|}
\hline \multirow[t]{2}{*}{ Districts } & \multicolumn{2}{|c|}{ Mapping Status } & \multicolumn{2}{|c|}{ Mapping Result } & \multicolumn{2}{|c|}{$\begin{array}{c}\text { Extrapolation } \\
\text { Required }\end{array}$} \\
\hline & Mapped & Unmapped & Zero & Non-Zero & No & Yes \\
\hline \multicolumn{7}{|l|}{ FSW } \\
\hline $\begin{array}{l}\text { Program } \\
\text { districts }\end{array}$ & 29 & - & - & 29 & 29 & - \\
\hline $\begin{array}{l}\text { Non-program } \\
\text { Districts }\end{array}$ & 15 & 31 & 11 & $4^{*}$ & 4 & 42 \\
\hline $\begin{array}{l}\text { TOTAL } \\
\text { MSM/TG }\end{array}$ & 44 & 31 & 11 & 33 & 33 & 42 \\
\hline $\begin{array}{l}\text { Program } \\
\text { districts }\end{array}$ & 31 & - & - & 31 & 31 & 0 \\
\hline
\end{tabular}




\begin{tabular}{lcccccc}
$\begin{array}{l}\text { Non-pro- } \\
\text { gram } \\
\text { districts }\end{array}$ & 13 & 31 & 8 & $5^{*}$ & 5 & 39 \\
$\begin{array}{l}\text { TOTAL } \\
\text { PWIDS }\end{array}$ & 44 & 31 & 0 & 36 & 36 & 39 \\
$\begin{array}{l}\text { Program } \\
\text { districts }\end{array}$ & 34 & & 2 & 32 & 32 & 2 \\
$\begin{array}{l}\text { Non-pro- } \\
\text { gram } \\
\text { districts }\end{array}$ & 10 & 31 & 7 & $3^{*}$ & 3 & 38 \\
TOTAL & 44 & 31 & 9 & 35 & 35 & 40 \\
\hline
\end{tabular}

* FSW Non-zero/Non-Program Districts: Baglung, Gorkha, Syangja, and Nuwakot ** MSM Non-zero/Non-Program Districts: Doti, Gorkha, Palpa, Salyan, Nuwakot ** PWID Non-zero/Non-Program Districts: Gorkha, Lamjung, Nywakot

Table 2: National size estimates of FSW

\begin{tabular}{lcc}
\hline \multirow{2}{*}{ Districts } & \multicolumn{2}{c}{ FSW } \\
\cline { 2 - 3 } Mapped & MIN & MAX \\
Unmapped & 43,254 & 53,499 \\
Total & 575 & 708 \\
\hline
\end{tabular}

* These estimates include all adjustment factors

Table 3: National size estimates of MSM/MSW/TG

\begin{tabular}{lrrrrrrrr}
\hline \multirow{2}{*}{ Districts } & \multicolumn{2}{c}{ TG } & \multicolumn{2}{c}{ MSW } & \multicolumn{2}{c}{ MSM } & \multicolumn{2}{c}{ Total } \\
\cline { 2 - 10 } & \multicolumn{1}{c}{ Min } & Max & \multicolumn{1}{c}{ Min } & Max & Min & Max & Min & Max \\
Mapped & 18,193 & 23,519 & 15,714 & 20,340 & 51,603 & 65,046 & 85,510 & 10,8905 \\
Unmapped & 511 & 697 & 218 & 302 & 1,770 & 2,246 & 2,499 & 3,245 \\
Total & 18,704 & 24,216 & 15,932 & 20,642 & 53,373 & 67,292 & 88,009 & 112,150 \\
Percentage* & $0.22 \%$ & $0.29 \%$ & $0.19 \%$ & $0.25 \%$ & $0.64 \%$ & $0.80 \%$ & $1.05 \%$ & $1.34 \%$ \\
\hline
\end{tabular}

* Percentage with respect to 2016 projected adult male population

Table 4: National size estimates of PWIDs

\begin{tabular}{lcccccc}
\hline \multirow{2}{*}{ Districts } & \multicolumn{2}{c}{ Male } & \multicolumn{2}{c}{ Female } & \multicolumn{2}{c}{ Total } \\
\cline { 2 - 7 } Mapped & Min & Max & Min & Max & Min & Max \\
Unmapped & 23,275 & 28,765 & 2,628 & 3,855 & 25,903 & 32,620 \\
Total & 1,297 & 1796 & 48 & 71 & 1,345 & 1,867 \\
Percentage* & 24,572 & 30,561 & 2,676 & 3,926 & 27,248 & 34,487 \\
Percentage with respect to adult female population & & $0.47 \%$ & $0.58 \%$ \\
\hline
\end{tabular}

*Percentage with respect to adult population

\section{DISCUSSION}

This paper is first study done extensively throughout the country including 44 districts for mapping and size estimation of key populations across Nepal. This study produced maps of all hotspots and estimated numbers of key populations in the majority of districts where intervention programs are being implemented. The study provided detailed local level estimates based on mapping data for high burden districts but relied mainly on extrapolated estimates from lower burden districts. This information is useful for quantifying the number of key populations who are visible and reachable by the program. Since the estimate was adjusted for double-counting, it can be used to help set targets, plan activities such as outreach, and measure coverage for venue-based key populations.

The adjustments factors were also applied to account for key populations who visited hotspots less frequently, or who did not visit hotspots at all. Therefore, the results can be used more broadly to help understand the magnitude of key populations who need to be reached with alternative (non-venue-based) service delivery models.

The study showed number of mapped hotspots of HIV key populations for FSW, MSM/MSW/TG and PWID were highest in Kathmandu valley within the country. This would be explained as due to increased population and the capital city of Nepal ${ }^{4}$.

The national estimate of FSW is maximum 54,207 and minimum 43,829 which represent $0.58 \%$ and $0.47 \%$ of the adult female population ${ }^{5}$. The maximum numbers of FSW were in Kathmandu Valley followed by Terai highway districts-Kailali, Sunsari and Rupandehi. As Terai highways districts have increased numbers of regular people mobility, explains increased numbers of FSW living within the highways districts 6 .

The national estimates MSM/MSW/TG is maximum 112,150 and minimum 88,009 which is between $1.34 \%$ and $1.05 \%$ of total adult male population ${ }^{7}$. The breakdown by subtype is 18,704 to 24,216 for TGs, 15,932 to 20,642 for MSWs, and 53,373 to 67,292 for $\mathrm{MSM}^{8}$. These estimates include both mapped and extrapolated districts and all adjustment factors. The maximum number of MSM/MSW/ TG were in Kathmandu Valley followed by Terai Highway districts- Kailali, Rupandehi and Kaski ${ }^{9}, 10$.

The national estimate of PWIDs is minimum 27,248 and maximum 34,487 , which is between $0.15 \%$ and $0.19 \%$ of the adult population. The breakdown by gender is 24,573 to 30,561 males and 2,676 to 3,926 females. These estimates include both mapped and extrapolated districts. The maximum numbers of PWID were in Kathmandu 
Valley followed by Terai Highway districts- Kaski, Bara and Banke ${ }^{11}$.

\section{CONCLUSION}

The present mapping study done at national level size estimation for key populations presents the overall status of key population with our country. The results for mapping exercises are expected to be useful in planning a new program to target key populations, formulation of policies and development of strategies that contribute to acquiring outcomes shaped through targeted interventions. The study will also help to fast track the response to achieve global 90-90-90 targets for the continuum of prevention to care. The country is updating its understanding of key population sizes and risk behaviors in different geographical area.

\section{Limitations of the study}

Mapping studies are subject to the inherent limitation of being cross-sectional, meaning that while they may count the majority of key populations who visit venues (hotspots) on a very regular basis, they count only a subset (perhaps a minority) of key populations who visit venues less frequently. This issue is compounded by the increasing use of mobile phones and social media sites for communication and hook-ups related to high-risk behavior. So as the time passes, it is possible that mapping studies may miss substantial subsets of key population members.

\section{Conflict of Interest}

None

\section{REFERENCES}

1. National Center for AIDS and STI Control (NCASC). HIV/AIDS situation of Nepal, Facts and Figure: 2016, Teku, Kathmandu, Nepal.

2. National Center for AIDS and STI Control (NCASC). Fact sheet 1: HIV epidemic update of Nepal: 2016,
Teku, Kathmandu.

3. National Center for AIDS and STI Control (NCASC). NationalHIV/AIDS Strategy(2006-2011). Department of Health Services. Ministry of Health and Population 2011, Government of Nepal, Kathmandu, Nepal.

4. National Center for AIDS and STI Control (NCASC). Mapping and size estimation of most at risk population in Nepal: 2011. Kathmandu, Nepal.

5. National Center for AIDS and STI Control (NCASC). Mapping and size estimation of most at risk population in Nepal: 2011. Female sex workers, male sex workers, transgender and their clients. Kathmandu, Nepal.

6. National Center for AIDS and STI Control (NCASC). Integrated biological and behavioral surveillance (IBBS) survey among female sex workers (FSWs) in Kathmandu Valley round V: 2015.

7. National Center for AIDS and STI Control (NCASC). Integrated biological and behavioral surveillance (IBBS) survey among female injecting drug users (FIDUs) in Kathmandu Valley. Kathmandu.

8. United Nations International Children's Emergency Fund (UNICEF). Survey of teenagers in seven districts of Nepal. Kathmandu, Nepal: 2001.

9. National Center for AIDS and STI Control (NCASC). Integrated biological and behavioral surveillance (IBBS) survey among female sex workers in Pokhara Valley round V: 2016. Kathmandu.

10. National Center for AIDS and STI Control (NCASC). Integrated biological and behavioral surveillance (IBBS) survey among men who have sex with men (MSM) and transgender (TG) in Terai highway Districts of Nepal, Fact sheet: 2016. Teku, Kathmandu, Nepal.

11. National Center for AIDS and STI Control (NCASC). Mapping and size estimation of most at risk population in Nepal: 2011. Injecting drug users. Kathmandu, Nepal. 